Journal of Environmental Science and Public Health

doi: 10.26502/JESPH.010

Volume 1, Issue 2

Research Article

\title{
Forest in Indigenous Health Care Systems: Perspective from Ethno-medicine
}

\author{
Melaku Getahun Jirata* \\ Department of Anthropology, Faculty of Social Sciences Wollega University, Ethiopia
}

*Corresponding Author: Melaku Getahun Jirata, Department of Anthropology, Faculty of Social Sciences, Wollega University, Ethiopia, Tel: +251912665369; E-mail: wakarka2012@ gmail.com

Received: 03 July 2017; Accepted: 28 July 2017; Published: 22 August 2017

\begin{abstract}
This study explored the role of forest resources in indigenous health care systems among the Oromo of Ethiopia. It is believed that forests are the repository as well as the source of medicinal plants for the treatment of both human and livestock ailments. Among the community of the study area, the drug extracted from medicinal plant species in the surrounding forest is used in the indigenous health care systems. Even though, the ethno-medical knowledge is the basis for modern medicine; nowadays facts are seemingly reversed because of some important factors evident in this era of globalization, and the contribution of the sector remain unacknowledged despite its bedrock contribution for the system. For traditional health care systems, forest is the ultimate source of medicine that helps in the treatment of both human and the livestock ailments. The study employed qualitative research method. Since the study is based on the lived experiences and the knowledge of the people in maintaining their health, qualitative research method is more pertinent in studying this problem. The findings show that forest is the source of bounty medicine for the local communities, through which the health of human and animal have been maintained for generation. It is thus, true that the synchronic existence of both traditional and modern medicine has been evident in the area.
\end{abstract}

Keywords: Ethno-medicine; Traditional medicine; Health care systems; Forest resources

\section{Introduction}

This study focused on the importance of forest resources, with the belief that forest is the source of traditional medicine used in maintaining the health of the society. Thus, it focuses on how the society extracts plant species of medicinal value from forest resources available in their environs in which they used to live. Different societies have 
various conceptions of health, disease, and illness. The standards people sets for health vary from culture to culture. Different ethnic groups recognized different illnesses, symptoms, and causes and have developed different health care systems and treatment strategies [1]. This study, thus, employs ethno-medical approach as pertinent approach to study insider's view 'emic perspective' on the subject matter. As Quinlan described ethno-medicine is the area of Anthropology that studies different societies' notions of health and illness, including how people think and act about wellbeing and healing. Medicine, like language, music, and politics is a subset of culture, which is situated locally [2].

Cultural factors are central issues in the health problems that confront the world today. The traditional medicine derived from cross-cultural health practices, exhibited in the alternative and complementary medicine used by people around the world, contributes new possibilities for physicians by expanding perspectives on health resources. The healing traditions found in every culture, have shown that traditional healing practices have effects on physiological, psychological, emotional, symbolic, and social levels, through its many healing mechanisms. UNEP [3] asserts that the importance of traditional medicine for the humans as well as animals in Africa both now and in the past is enormous. UNEP further argued that even though African traditional medicine involves some aspects of mind-body interventions and use of animal-based products, it is largely plant-based. Many of the plants used were collected from the wild, as there were few instances of domestication of the significant medicinal plants.

Traditional medical practices can make important contributions to future health care, just as herbs contributed to the development of the biomedical pharmacopoeia [4]. Traditional medicinal knowledge maintained by specific Cultural [social] group is also essential for addressing public health needs to assess communities' health needs, develop appropriate health policies and programs, and ensure adequate and culturally competent health services [5]. The health needs of communities vary widely, requiring an understanding of each community's perceptions of health and illness to develop appropriate services. Public health initiatives require knowledge of culture to change the behaviors and lifestyles associated with an increased incidence of disease. Addressing the effects of culture on health is an important issue for everyone, not just physicians, because disease in any group affects society as a whole [5].

However, studies about the relationship between forest and the human with respect to the values of forest resources for the extraction of traditional medicine have been owed little or no attention in the scientific arena. Thus, traditional medicine and the associated knowledge maintained by the indigenous peoples found elsewhere have laid the base for modern medical practices; it has been neglected for long time. Even, the health policy of various countries is exclusive or monopolistic, which only allow the practices of modern biomedical practices as lawful. Hence, this study aimed at filling these gaps by studying the indigenous health maintenance systems of the people and the use of forest resources in traditional medical systems by providing few insights about the importance of forest resources in traditional medicine for human and livestock ailment among the Oromo. For the people of the study area, all kinds of traditional medicine for human and livestock have been collected from forest resources based on the indigenous knowledge of the local community. The community has experts [healers] that have the knowledge of extracting medicine from forest used to treat different diseases. As indigenous peoples found elsewhere, the 
Oromo community of the area thus maintained similar intelligence. The knowledge of extracting medicine from forest resources is possible only by experts in the matter, and all societies have these experts in their socio-cultural tradition.

\section{Material and Methods}

This study employed qualitative research methods. Both primary and secondary data sources were used to compile the data for the study. Interviews, non-participant observation, focus group discussions, case study, and document analysis (published) were the instruments used to obtain reliable data for the study. Two forms of interviewsunstructured interviews and semi-structured [in-depth] interviews were held with different community members. Both interviews, parallel with other techniques, were conducted in January, April, and May 2015. Unstructured interviews were held with members of the local community, including individuals of different backgrounds like sex, age, social status, religious faiths, occupation, and literacy background, such as elders, youths, government officials, farmers, merchants, students, and teachers of different levels. Unstructured interviews were held in any places and time available without reservation. In-depth interviews were held with key informants selected on purposive base by the researcher based on their prior knowledge in relation with the objective of this study. The topics raised under unstructured interviews were assessed in detailed with this method. In-depth interviews were conducted in ten unit Administrations among twenty-seven unit administrations of the Nole District []. The researcher on purposive base selected these areas.

In the entire field stay, twenty in-depth interviews, which took an average of one and half hour with each interviewee, were conducted. The responses of the interviewee were documented by note taking and tape-recording. This tool was used to get detailed data for the entire frame of this study, and to justify the anecdotal information encountered when unstructured interviews were conducted. In the entire field stays, the researcher in the selected places of study area conducted non-participant observations. The non-participant observations were used to observe the environmental facts such as the forest resources composition of the area, and the plant species used for traditional medicine found in the area. The study also employed relevant documents as source of data. Data from these sources, thus, were used for the entire frame of the study.

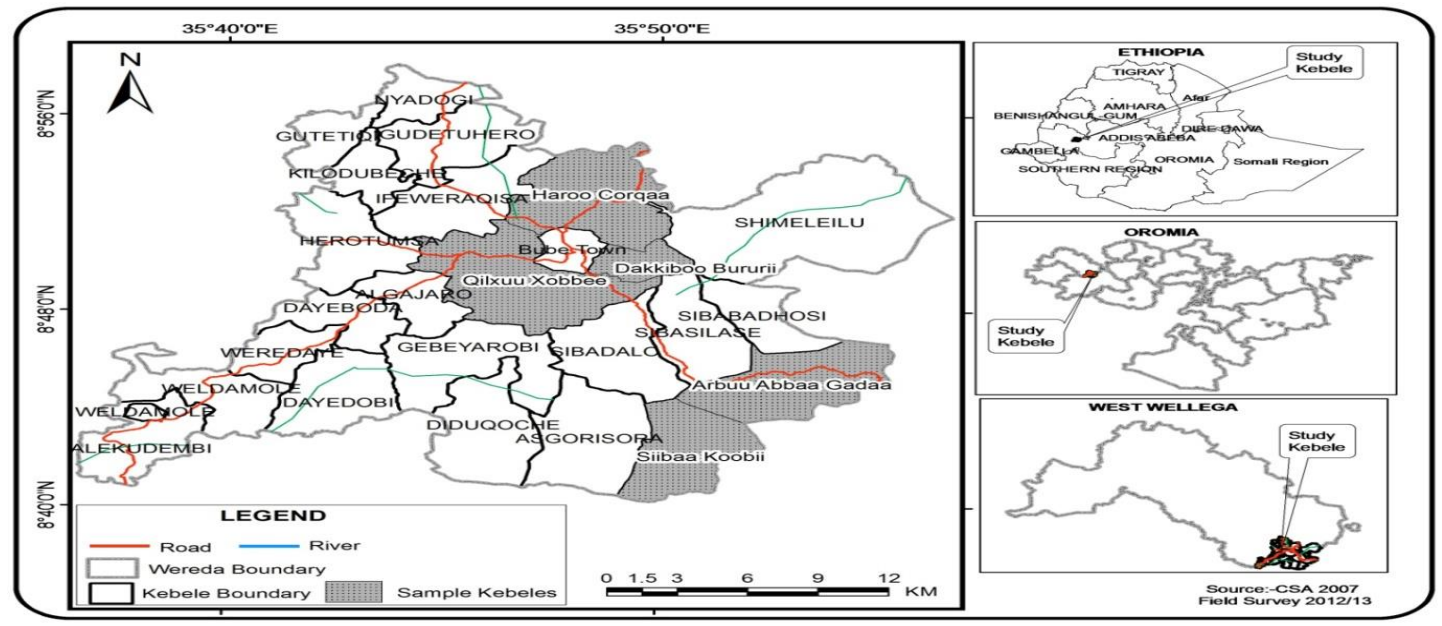

Map 1: Location map of the study area. 


\section{Results and Discussion}

The data obtained reveal that among all other significances of forest resource, medicinal and religious significances are magnificent. Forest resources, in this case are source of traditional medicine, used to treat both human and livestock diseases. It is culture for the society of the study area to utilize traditional medicine, extracted from forest resources by the traditional healers. The community has been used the medicine that have been extracted from the forest found in their environs for generations since time immemorial. With the introduction of biomedical or modern health care systems, the society become pluralist, by being kept using their indigenous means of maintaining the health of both human and livestock. The synchronic existences of both traditional and modern health care systems are evident in the area nowadays.

Traditional medicine and the practices of maintaining health among the rural people of the study area has been valued and owed respect from the member of the community, and thus the practitioners have owed respect from the community. However, later they [practitioners like healers and traditional drug venders] have enjoyed lowest social position by being practitioner of traditional medicine. This label of low status has been related with the expansion of Christianity in the area, which condemns the practices of traditional medicine, relating it to witches and magic, which is considered as evil-deed and contradictory to the Christian doctrine.

However, majority of the community member continues to use traditional medicine, despite the massive pressure from alien cultural tradition like western Christianity. Thus, the new generation [nowadays] loose expertise of their ancestor, which have negative impacts on both the well-being and the knowledge base of the society, and the forest resources composition [coverage] of the area. Thought, the forest resources of the area have been protected for its values the community attached to the forest composition of the area. Moreover, despite the negligence that has been encountered, good parts of the society have kept using the medicine extracted from the forest resource that has been inherited from their ancestor. What is important is that the introduction of alien cultural elements and Christianity to the area could not alter the long existing tradition of the people, and the people still highly practicing the traditional medical systems in maintaining the health of human and livestock.

The finding shows that the practices of health maintenance among the Oromo of the study area is institutionalized in their cultural tradition and could not be seen in isolation from other aspects of the society. Hence, the entire aspects of the society are functionally related and the dynamics of relationship is magnified that could help in the protection of the forest composition of the area for generations. Traditional medicine has defined by the World Health Organization as the sum total of all the knowledge, beliefs, and practices that are used in diagnosis, prevention, and elimination of physical, mental, or social imbalance. Thus, it relies exclusively on practical experiences and observation handed down from generation to generation. It is a product of social institutions and cultural traditions, which have evolved over many centuries to enhance health [6]. The finding indicates that this definition has been true to the belief, knowledge, and practices of the community of the study area holds about the traditional medicinal practices embedded in their culture. 
The data obtained from in-depth interview with one key informant [traditional healer] of the area reveals that God created human beings with all necessary things in the natural environments. He said, "If we know and aware about how the natural environments are precious for our survival, even other social problems will be curbed. However, we exploit wrongly the nature and then we suffer from different problems, including disease and starvation of human and animals."

Indeed, he stated that majority of the Nole Oromo's have maintained the knowledge of plant species which have medicinal importance found in the forest composition of the area. It is this resource and the knowledge of extracting medicine from this resource that have been maintained the health of human and livestock of the community for generation, even before and after the introduction of modern health care system to the area for both human and livestock ailments, which is the recent history of the people of the study area.

The practitioners of traditional medicine are collectively known as (ogeessa qoricha aadaa), loosely translated to English to mean the experts of tradition medicine or traditional healers. Among the Nole Oromo, traditional healers are individuals who are specialists of different types of human and livestock ailment. These traditional healers are categorized into two: spiritual and technical healers. Among the Oromo of the study area, the well-known spiritual healer that has been curing patients with different types of illnesses is the religious leader of the Oromo indigenous religion, called Ayyaantuu [7]. He is believed to possess the spirit Ayyaana [8] and mediates between human beings and God Waaqa [9]. Here, what is interesting is that traditional medical practices has been maintained strong relation with the indigenous religion of the community, in which religion and health are inseparable for the society. The second type of traditional healers, technical healers and further categorized into two areas of specializations, called herbalists and bonesetters. Herbalists use forest trees and various leaves in preparing medicines for the patients. They also deal with animal ailments, and thus, they prepare medicines from forest plant species. They have the knowledge of anatomical and physiological function of the human and animal body, and preparing traditional medicines from different parts of medicinal plant species. They possess the knowledge of types of ailments, based on the symptoms of the illness of both human beings and animals, and thus, they use traditional medicine prepared from plant species in healing the sickness. The other type of healers under this category is bonesetter. They are technical healers, and have specialized knowledge of human and animal anatomical structures and physiological functions of the normal body. With their knowledge, they can easily detect the type of ailment, and treat accordingly. Moreover, they use materials extracted from forest, especially, some type of plant species for tying the broken bone. They stick and tie the broken part with other parts of the body, and thus, a plant stick used in this process is believed to have medicinal importance in healing the broken bone.

\section{Some Medicinal Plant Species of the Study Area}

Among the Nole Oromo, the plant species that have medicinal importance, for both human and livestock ailment includes Eebicha (Vernonia amydalina), used to treat ascariasis and flariasis in humans. Ceekaa (Calpurnia aurea), used to treat headache and stomachache in humans and skin disease in livestock; Ulmaayii (lausena anisata), used to treat toothache in humans; Bakkannisa (Croton macrostachyus), used to treat hookworm, tinia corpis (roobbii), 
and wound in humans; Laaftoo (Acacia brevispica), used to treat stomachache and snakebite. These are to give but a few examples of the medicinal plants in common use among the Oromo of the study area.

The summary of plant species, their habitat, the plant part used for preparing medicine, the types of disease treated by each, and for whom (humans or livestock) it is used, based on the data obtained from key informants of the study area is presented in the following Table 1.

\begin{tabular}{|c|c|c|c|c|c|c|c|c|}
\hline \multicolumn{5}{|c|}{ Plant Species } & \multicolumn{4}{|c|}{ Uses For } \\
\hline No & Local Name & Scientific Name & $\begin{array}{l}\text { Habit } \\
\text { Type }\end{array}$ & $\begin{array}{l}\text { Plant Part } \\
\text { used for } \\
\text { Medicine }\end{array}$ & Human & $\begin{array}{l}\text { Used to } \\
\text { treat }\end{array}$ & $\begin{array}{l}\text { Livesto } \\
\text { ck }\end{array}$ & $\begin{array}{l}\text { Used to } \\
\text { Treat }\end{array}$ \\
\hline 1. & Laaftoo & Acacia brevispica & Tree & $\begin{array}{l}\text { Root and } \\
\text { Bark }\end{array}$ & \multicolumn{2}{|c|}{$\begin{array}{l}\text { Stomach ache and Snake } \\
\text { bite }\end{array}$} & \multicolumn{2}{|c|}{ Unidentified yet } \\
\hline 2. & Muka-arbaa & $\begin{array}{l}\text { Albizia } \\
\text { schimperiana }\end{array}$ & Tree & Bark & \multicolumn{2}{|c|}{ Stomachache } & \multicolumn{2}{|c|}{ Unidentified yet } \\
\hline 3. & Bakkannisa & $\begin{array}{l}\text { Croton } \\
\text { macrostachyus }\end{array}$ & Tree & $\begin{array}{l}\text { Leaf and } \\
\text { latex }\end{array}$ & \multicolumn{2}{|c|}{$\begin{array}{l}\text { Hookworm Tinia corpis } \\
\text { (roobbii) and wound }\end{array}$} & \multicolumn{2}{|c|}{ Unidentified yet } \\
\hline \multirow[t]{3}{*}{4.} & \multirow[t]{3}{*}{ Laaftoo } & Acacia brevispica & Tree & Bark & \multicolumn{2}{|c|}{ Snake bite } & \multicolumn{2}{|c|}{ Unidentified yet } \\
\hline & & Acacia abyssinica & Tree & Bark & \multicolumn{2}{|c|}{ Snake bite } & \multicolumn{2}{|c|}{ Unidentified yet } \\
\hline & & Acacia torties & Tree & Bark & \multicolumn{2}{|c|}{ Snake bite } & \multicolumn{2}{|c|}{ Unidentified yet } \\
\hline 5. & Qilхии & Ficus vasta & Tree & $\begin{array}{l}\text { Latex and } \\
\text { leaf }\end{array}$ & \multicolumn{2}{|c|}{ Snake bite } & \multicolumn{2}{|c|}{ Unidentified yet } \\
\hline 6. & Afarfattuu & Dracaena studneri & Shrub & Entire part & \multicolumn{2}{|c|}{$\begin{array}{l}\text { Protect evil spirit from } \\
\text { family }\end{array}$} & \multicolumn{2}{|c|}{$\begin{array}{l}\text { prevent lightening } \\
\text { from animals and } \\
\text { animal cage }\end{array}$} \\
\hline 7. & Botoroo & $\begin{array}{l}\text { Stereospermum } \\
\text { kunthianum }\end{array}$ & Tree & Latex, Bark & \multicolumn{2}{|c|}{$\begin{array}{l}\text { Toothache and prevent a } \\
\text { man from evil eye and } \\
\text { man-made poison }\end{array}$} & \multicolumn{2}{|c|}{ Unidentified yet } \\
\hline 8. & Qomonyo & $\begin{array}{l}\text { Brucia } \\
\text { antidysenterica }\end{array}$ & Shrub & $\begin{array}{l}\text { Whole } \\
\text { plant }\end{array}$ & \multicolumn{2}{|c|}{$\begin{array}{l}\text { Different skin disease, and } \\
\text { evil eye, dearhia }\end{array}$} & \multicolumn{2}{|c|}{ Unidentified yet } \\
\hline 9. & Adaamii & $\begin{array}{l}\text { Euphorbia } \\
\text { candelabrum }\end{array}$ & Tree & Latex & \multicolumn{2}{|c|}{ Ascariasis and gonorrhea } & \multicolumn{2}{|c|}{ Unidentified yet } \\
\hline 10. & Qabaricho & $\begin{array}{l}\text { Echinops } \\
\text { kebericho }\end{array}$ & Herb & Root & \multicolumn{2}{|c|}{$\begin{array}{l}\text { Protect and heal from evil } \\
\text { spirit }\end{array}$} & \multicolumn{2}{|c|}{ Unidentified yet } \\
\hline 11. & Beeftii & $\begin{array}{l}\text { Warburgia } \\
\text { ugandensis }\end{array}$ & Tree & Leaf & \multicolumn{2}{|c|}{$\begin{array}{l}\text { Malaria, and } \\
\text { stomachache, }\end{array}$} & \multicolumn{2}{|c|}{ Trypanosomaisis } \\
\hline 12. & Ceekaa & Calpurnia aurea & Shrub & Leaf & \multicolumn{2}{|c|}{$\begin{array}{l}\text { Headache and } \\
\text { stomachache }\end{array}$} & \multicolumn{2}{|c|}{ Skin disease } \\
\hline 13. & Eebicha & $\begin{array}{l}\text { Vernonia } \\
\text { amydalina }\end{array}$ & Shrub & Leaf & \multicolumn{2}{|c|}{ Ascariasis and Flariasis } & \multicolumn{2}{|c|}{ Unidentified yet } \\
\hline 14. & Agamsa & Carissa spinarum & Shrub & $\begin{array}{l}\text { Leaf and } \\
\text { fruit }\end{array}$ & \multicolumn{2}{|c|}{ Ascariasis and Evil eye } & \multicolumn{2}{|c|}{ Unidentified yet } \\
\hline
\end{tabular}




\begin{tabular}{|c|c|c|c|c|c|c|}
\hline 15. & Andoodee & $\begin{array}{l}\text { Phytolacca } \\
\text { dodecandira }\end{array}$ & Shrub & $\begin{array}{l}\text { Leaf and } \\
\text { fruit }\end{array}$ & Scabies and herpes zoster & Unidentified yet \\
\hline 16. & Tamboo & Nicotina tabacum & Shrub & $\begin{array}{l}\text { Leaf and } \\
\text { seed }\end{array}$ & Snake bite & Leech infestation \\
\hline 17. & Pappayaa & Carica papaya & Shrub & Fruit & Skin disease & Unidentified yet \\
\hline 18. & Hadaa & Guizotia scabra & Herb & $\begin{array}{l}\text { Leaf and } \\
\text { flower }\end{array}$ & Snake bite & Unidentified yet \\
\hline 19. & Kusaayee & Lippie javanica & Herb & Whole part & Snake bite & Unidentified yet \\
\hline 20. & Coqorsa & Cynodon dactylon & Herb & Whole part & Wound & Unidentified yet \\
\hline \multirow[t]{2}{*}{21.} & \multirow[t]{2}{*}{ Reejjii } & $\begin{array}{l}\text { Vernonica } \\
\text { auriculifera }\end{array}$ & Shrub & Leaf & Wound & Unidentified yet \\
\hline & & Caylusa abyssinica & Shrub & Leaf & Getting rid of impotency & Unidentified yet \\
\hline 22. & Buna & Coffee Arabica & Shrub & Seed & Headache, stomachache, & Unidentified yet \\
\hline 23. & $\begin{array}{l}\text { Dhummuиgg } \\
\text { aа }\end{array}$ & $\begin{array}{l}\text { Justicia } \\
\text { schimperiana }\end{array}$ & Shrub & Leaf & $\begin{array}{l}\text { Used by the healer to } \\
\text { remove Evil spirit from } \\
\text { the patient. }\end{array}$ & Unidentified yet \\
\hline 24. & Geeshoo & Rhamnus prinoides & Shrub & Leaf & Tonsillitis & Unidentified yet \\
\hline 25. & Harangama & Caesal decapetala & Shrub & Root & Cough and headache & Unidentified yet \\
\hline 26. & Raamsoo & Cassia petersiana & Shrub & Leaf & Skin disease & Unidentified yet \\
\hline 27. & Ulmaayii & lausena anisata & Shrub & Leaf & Toothache & Unidentified yet \\
\hline 28. & $\begin{array}{l}\text { Qoricha } \\
\text { Bowwuи }\end{array}$ & $\begin{array}{l}\text { Cynoglossum } \\
\text { amplifolium }\end{array}$ & Herb & Leaf & Headache & Unidentified yet \\
\hline 29. & Ejersa & Olea europaea & Tree & Leaf & Stomachache, evil spirit & Unidentified yet \\
\hline 30. & Andodee & $\begin{array}{l}\text { Phytolacca } \\
\text { dodecandra }\end{array}$ & Shrub & Fruit & $\begin{array}{l}\text { To protect external } \\
\text { parasites }\end{array}$ & Unidentified yet \\
\hline
\end{tabular}

Table 1: Ethno pharmacology of Medicinal plant Species among the Oromo of the Study Area.

The data obtained reveal that there are no beliefs that the whole parts of a medicinal plant species used for preparing medicine. Rather it is the indigenous knowledge and practices of the community that helps the specialists to extract the drug from the parts of the medicinal plant species. For instance, medicinal plant species called Laaftoo (Acacia brevispica) the root and bark are used to prepare drug for the treatments of patients with problems of stomachache and snakebite in humans. Similarly, other medicinal plant species, parts of the plant, such as leaf, latex, and seeds are uses to prepare drug to cure both humans and livestock ailment. Indeed, in the case of shrubs, there are instances in which the entire parts of the plant species uses for treating the patient. Thus, for herbs like Qabarichoo (Echinops kebericho) the root is used to smoke by the patient to treat patients sick from evil eye and other spiritual ailment. 


\section{Conclusion}

In general, the study reveals that among the Oromo of the study area, forest resources have medicinal value. Cutoff such plant species and their seedling are strictly prohibited in the culture of the people. In the study area, plants of significant medical importance never cut down for any reason. Thus, an individual member of the community acts whom violet the rule accused and punished by the elders of the community for his/her wrong deed. However, the emergence of new religious sects and the expansion of modern health care systems have their own impacts on the forest resources and the knowledge base of the society.

Though, forest are not only the mere source of medicine in the history of human being; for indigenous peoples it is beyond that boundary, embedded in entire aspects of their lives that have been meaningful in their life. Moreover, as seen above, this study is incomplete, since recording the entire aspects of the society, which are embedded in their socio-cultural, historical, spiritual, economic, and political aspects are difficult in such a single mini study. I recommend individuals and organizations for further study on the subject matter that would help for the revival of traditional and original identity.

\section{References}

1. Zerihun D. Introduction to Sociocultural Anthropology for Health Science Students of Higher Learning Institution in Ethiopia: A Lecture Note. Debub University (2004).

2. Marshal QB. 'Ethnomedicine'. In Merrill Singer and Pamela I. Erickson. A Companion to Medical Anthropology. Blackwell: USA (2011): 381-404.

3. UNEP. Indigenous Knowledge in Disaster Management in Africa. Nairobi, Kenya (2008).

4. Winkelman M. Culture and Health: Applying Medial Anthropology. USA: Jossey- Bass (2009).

5. WHO. WHA Resolution on Traditional Medicine. Geneva (2009).

6. Feyisa D. The Origin of the Oromo: Reconsideration of the Theory of the Cushitic Roots. In the Journal of Oromo Studies 5 (1998): 1-2.

7. Mohammed H. The Oromo of Ethiopia: A History 1570-1860. New York: Cambridge University Press (1994).

8. Alemayehu, Haile, Boshi Gonfa, Daniel Deressa, et al. History of the Oromo to the Sixteenth Century. $2^{\text {nd }}$ Edn. Finfinnee: Oromiyaa Culture and Tourism Bureau (2006).

9. Bartels L. Oromo Religion: Myths and Rites of the Western Oromo of Ethiopia- An Attempt to Understand. Berlin: Dietrich Reimer Verlag (1983). 